Trab. Ling. Aplic., Campinas, 44(2): 233-246, Jul./Dez. 2005

\title{
OS ESTUDOS DA TRADUÇÃO E OS DICIONÁRIOS
}

\author{
PHILIPPE HUMBLÉ* \\ (Universidade Federal de Santa Catarina)
}

\begin{abstract}
RESUMO
A tradução tem diretamente a ver com dicionários. Não se fazem traduções sem eles. No entanto, nem os Estudos da Tradução têm se ocupado com os dicionários, nem a meta-lexicografia com a tradução. Os dicionários não parecem influenciar a tradução, nem os lexicógrafos são vistos como sendo tradutores. Isso é, em parte, porque os lexicógrafos seriam tradutores 'automáticos', que não têm escolha quando traduzem, enquanto a escolha, e a dificuldade da escolha, é vista como o que caracteriza o trabalho do tradutor. No entanto, se compararmos os mesmos verbetes em alguns dicionários, onde aparecem exemplos que, aparentemente, só poderiam ser traduzidos de uma única maneira, percebemos que as traduções são várias e que, portanto, o lexicógrafo é um tradutor. Seu trabalho poderia ser analisado sob o olhar do tradutólogo e isso daria lugar a conclusões interessantes. Este artigo propõe que a relação Lexicografia / Estudos da Tradução seja investigada de maneira mais sistemática.
\end{abstract}

Palavras-chave: tradução, lexicografia, contexto.

\begin{abstract}
Translation bears an immediate relationship to dictionaries. No translation is done without them. Even so, students of translation have not shown much interest in the past in lexicography, nor meta-lexicographers in translation. Translation does not seem to be influenced by dictionaries, and lexicographers are not seen as translators. This is, in part, because lexicographers are supposed to be 'automatic translators', who do not make any choices when translating, whereas 'choice', or the difficulty to choose, is seen as what foremost characterises the translator's craft. Nevertheless, when we compare identical entries in different dictionaries, containing examples that, apparently, could only be translated in one single way, one notices that translations differ and that, consequently, lexicographers are translators in their own way. Their craft can be analysed from the point of view of translation research and this may yield interesting conclusions. This article proposes that the relationship between Lexicography and Translation Studies be researched in a more systematic way and gives a number of concrete examples.
\end{abstract}

Key-words: translation, lexicography, context.

\section{OS TRADUTORES E A LEXICOGRAFIA}

Talvez seja porque a relação entre tradutor e dicionário é tão evidente que os Estudos da Tradução até agora quase não se ocuparam com ela. Não achei nenhum artigo que

\footnotetext{
*Agradeço o apoio da CAPES que, por meio da bolsa de pós-doutorado 0250-03-1, possibilitou a pesquisa feita para este artigo.
} 
tratasse de dicionários na literatura tradutológica e uma obra de referência bastante completa como a Routledge Encyclopedia of Translation Studies não inclui verbetes nem para 'dicionário', nem para 'lexicografia', nem menciona nenhuma dessas palavras no seu índice. Aliás, é extremamente raro que a palavra 'dicionário' seja usada no texto. Neste artigo eu gostaria de mostrar que os dicionários não dão traduções 'objetivas' como se costuma pensar, dispensáveis de toda análise crítica. Além disso, os problemas que os lexicógrafos-tradutores enfrentam são muito mais parecidos com os problemas dos tradutores literários que os dos tradutores técnicos.

No caso da lexicografia como disciplina acadêmica, a mesma situação reina, embora de maneira menos gritante. A lexicografia ignora quase totalmente os Estudos da Tradução, tal como os Estudos da Tradução a ignoram. Encontrei, com efeito, somente um artigo que tratasse do assunto ${ }^{1}$. Se digo que a Lexicografia 'quase' ignora os problemas de tradução, e não totalmente, é porque nesta área há pelo menos, desde tempos talvez imemoriais, questionamentos sobre a possibilidade de 'equivalência' entre palavras de línguas diferentes, sobre o que significa 'tradução'.

No entanto, e apesar desta indiferença mútua, parece óbvio que um dicionário bilíngüe não deixa de ser um gigantesco esforço de tradução de uma língua em outra, como um todo ou parcialmente. É verdade que se trata de uma 'tradução' que não corresponde exatamente ao que entendemos tradicionalmente por 'tradução', ou ao que os teóricos dos Estudos da Tradução têm em mente quando estudam o fenômeno. Um dicionário não é um 'texto' se aplicamos a ele critérios de 'coerência' e 'coesão'.

Há, aliás, outra diferença importante quando comparamos a tradução praticada num dicionário bilíngüe com uma tradução comum: as traduções que encontramos num dicionário bilíngüe podem ser classificadas segundo seu tamanho: palavras, primeiro, depois expressões idiomáticas e finalmente exemplos. É uma classificação que não parece muito sofisticada, mas que é de importância. Examinemos estes diferentes tipos de tradução mais de perto.

\section{PALAVRAS, EXPRESSÕES IDIOMÁTICAS E EXEMPLOS}

A tradução de 'palavras' enquanto entidades mínimas carregadoras de significado é um problema que tem a ver com o problema - filosófico - implicado pelo recorte que fazem as diferentes línguas humanas do mundo e da experiência. A tradução de palavras isoladas num dicionário tem relação com os Estudos da Tradução no sentido em que nessa problemática é questionada a possível equivalência de uma palavra numa língua fonte com outra em uma língua alvo. É um assunto de que os teóricos da tradução tratam quando falam em conotação e denotação, ou quando se discute a recorrente questão da tradução 'palavra-por-palavra' ou 'sentido-por-sentido'. A tradução da palavra enquanto

${ }^{1}$ Atkins B.T.S. (Ed.) 1998 Using Dictionaries. Studies of Dictionary Use by Language Learners and Translators. Niemeyer. 
Trab.Ling.Aplic., Campinas, 44(2) - Jul./Dez. 2005

palavra aparece também como uma questão problemática para tradutores quando se trata da tradução de rimas, aliterações, jogos de palavras ou gíria. No entanto, neste último caso, o uso que os tradutores fazem do dicionário é bastante particular. Não coincide com o uso dos usuários comuns, que não costumam se ocupar com pesquisas estilísticas.

A tradução de expressões idiomáticas, provérbios e metáforas, que também se encontram nos dicionários bilíngües, se aproxima mais do trabalho tradicional dos tradutores. Trata-se, com efeito, se não de textos, pelo menos de conjuntos de, no mínimo, duas palavras. É uma problemática que seria, portanto, legítima aos olhos dos teóricos da tradução, mas que eles preferem tratar sob o ângulo de 'técnicas de tradução' e, mais especificamente, sob a perspectiva da 'compensação'. A tradução de 'desse mato não sai cachorro' é um problema ao que podem ser confrontados tanto lexicógrafos como tradutores, mas a maneira de resolvê-lo será diferente. Se um tradutor pode decidir não traduzir e compensar de outra maneira em outro lugar, o lexicógrafo não tem essa opção.

Os 'exemplos' são a porção de texto traduzido mais extensa que se possa encontrar num dicionário e é o que nos interessa mais particularmente aqui. No caso dos exemplos, dependendo do seu tamanho, os lexicógrafos se tornam tradutores no sentido tradicional da palavra, no sentido em que Mona Baker, Venuti e outros falariam desta ocupação. É do caso dos exemplos que eu gostaria de tratar de maneira mais pormenorizada, mas primeiro eu preciso indicar brevemente de que maneira os lexicógrafos costumam olhar para a tradução.

\section{OS LEXICÓGRAFOS E A TRADUÇÃO}

O clássico Manual of Lexicography de Zgusta encara a tradução basicamente como tropeçando na questão do 'anisomorfismo'² das línguas, o fato delas não coincidirem no recorte que elas fazem da realidade. Os lexicógrafos têm suas idéias sobre a arte de traduzir e Zgusta dá um bom exemplo da tônica geral:

É por causa deste anisomorfismo que a tarefa de traduzir textos de uma língua para outra não é simples; no entanto ela é possível, porque o tradutor não é obrigado a produzir uma tradução palavra-por-palavra. Vejamos um exemplo muito simples: num determinado trecho de um romance uma pessoa é caracterizada pela maneira grosseira de se expressar. Isto é mostrado pelo uso de palavras grosseiras que se referem a, por exemplo, comida. Se a língua alvo por ventura não possuir equivalentes completos (isto é, se não existem palavras equivalentes que designem comer com a conotação de grosseiro), o tradutor não terá outra solução a não ser usar aquelas palavras da língua alvo que têm a mesma designação (comer) e que caracterizam o locutor pela escolha de outras expressões grosseiras. Desta forma, não há correspondência absoluta e total entre algumas palavras

${ }^{2}$ Anisomorfism: "the differences in the organization of designates in the individual languages and by other differences between languages." (Zgusta, 1971:294) 
HUMBLÉ - Os estudos da tradução e os dicionários

isoladas do original e as da tradução, mas o sentido da passagem original como um todo é transmitida pelo seu equivalente traduzido. ${ }^{3}$ (Zgusta 1971:296-297; minha tradução.)

Como dá para perceber por esta passagem, a tradução é vista por Zgusta pela ótica já bastante antiga, embora sempre atual, da dificuldade da tradução inerente à nãoequivalência das línguas. Daí a necessidade de uma tradução que não seja palavra-porpalavra e, sim, sentido-por-sentido. Em outras palavras, Zgusta faz uma apologia da inevitabilidade do procedimento da compensação.

A meta-lexicografia, que eu saiba, se manteve a esses princípios básicos até hoje e eu não consegui achar nada que apontasse na direção de uma problematização mais avançada. Isto significa que não existe problema algum? Eu acho que não. Apenas significa que os problemas não são de tamanha importância que impeçam a confecção de dicionários bilíngües bons, dicionários nos quais os lexicógrafos atuam como tradutores, mas sem aparentemente os problemas tradicionais dos tradutores. É necessário recalcar, no entanto, que, como já foi apontado, a grande diferença com a tradução no sentido tradicional da palavra é que uma tradução 'sentido-por-sentido' é muitas vezes impensável num dicionário, porque este tipo de tradução implica a inserção de uma palavra ou de um grupo de palavras num 'texto'. O que caracteriza o sentido, mais do que nada quando a palavra 'sentido' é usada na expressão sentido-por-sentido (e oposta a 'palavra-porpalavra'), é o fato de que o sentido é adquirido em parte pela palavra em si e em parte pelo contexto.

A grandíssima maioria das traduções num dicionário são, portanto, necessariamente traduções palavra-por-palavra, porque o sentido preciso só pode ser dado pelo texto, que está em possessão do usuário e não pode ser imaginado adequadamente pelo lexicógrafo. Assim sendo, a tradução num dicionário é muitas vezes uma tentativa do lexicógrafo de imaginar de que maneira uma tradução sentido-por-sentido poderia acontecer. Daí o uso de sinônimos que acompanham a tradução, ou de 'rubricas' (labels) que traduzem, de uma maneira relativamente deficiente, a imaginação do lexicógrafo ou, antecipando o que vou desenvolver a seguir, a sua capacidade de 'ficcionalização'.

${ }^{3}$ This lexical anisomorphism causes that the task of translating texts from one language into another is not easy; still it is possible, because the translator is not obliged to produce a word-for-word translation. To take an oversimplified example: a person in a novel is characterized by his impolite speech in a passage, this is expressed by his use of impolite words referring to, say, eating. If the target language happens to have no full equivalents (i.e. no equivalent words designating eating with the connotation of being impolite), the translator cannot but use those words of the target language which have the same designation (eating), and characterizes the speaker by the choice of some other impolite expressions. In this way, there is no absolute one-to-one correspondence between some single words of the original and those of the translation , but the whole meaning of the original passage is conveyed by its translated counterpart. (Zgusta 1971:296-297) 


\section{EXEMPLOS}

Como já foi mencionado, a tradução de exemplos é o que mais se aproxima ao trabalho de tradução, tal como ele é compreendido tradicionalmente. Mas talvez seja preciso primeiro definir o que eu entendo por 'tradução'.

É claro que os dicionários, por muito que eles se ‘inspirem' uns nos outros, nunca são iguais. No caso dos dicionários bilíngües, há os que são mais completos que outros, os que oferecem mais alternativas ou que fazem uma subdivisão mais detalhada do significado de uma palavra. A diferença geralmente é de quantidade. As mesmas palavras são traduzidas da mesma maneira e o lexicógrafo aparentemente não tem muita escolha. E onde não há escolha, não há criação. As decisões a serem tomadas se reduzem portanto a problemas de número: 'será que eu expando o sentido da palavra tanto até incluir a tradução X?'; 'será que eu levo em conta o contexto Y em que a palavra significa Z?' Assim o lexicógrafo é verdadeiramente tradutor apenas em certas partes do verbete. Exemplificamos com um verbete do Lexibase Pro Inglês-Español.

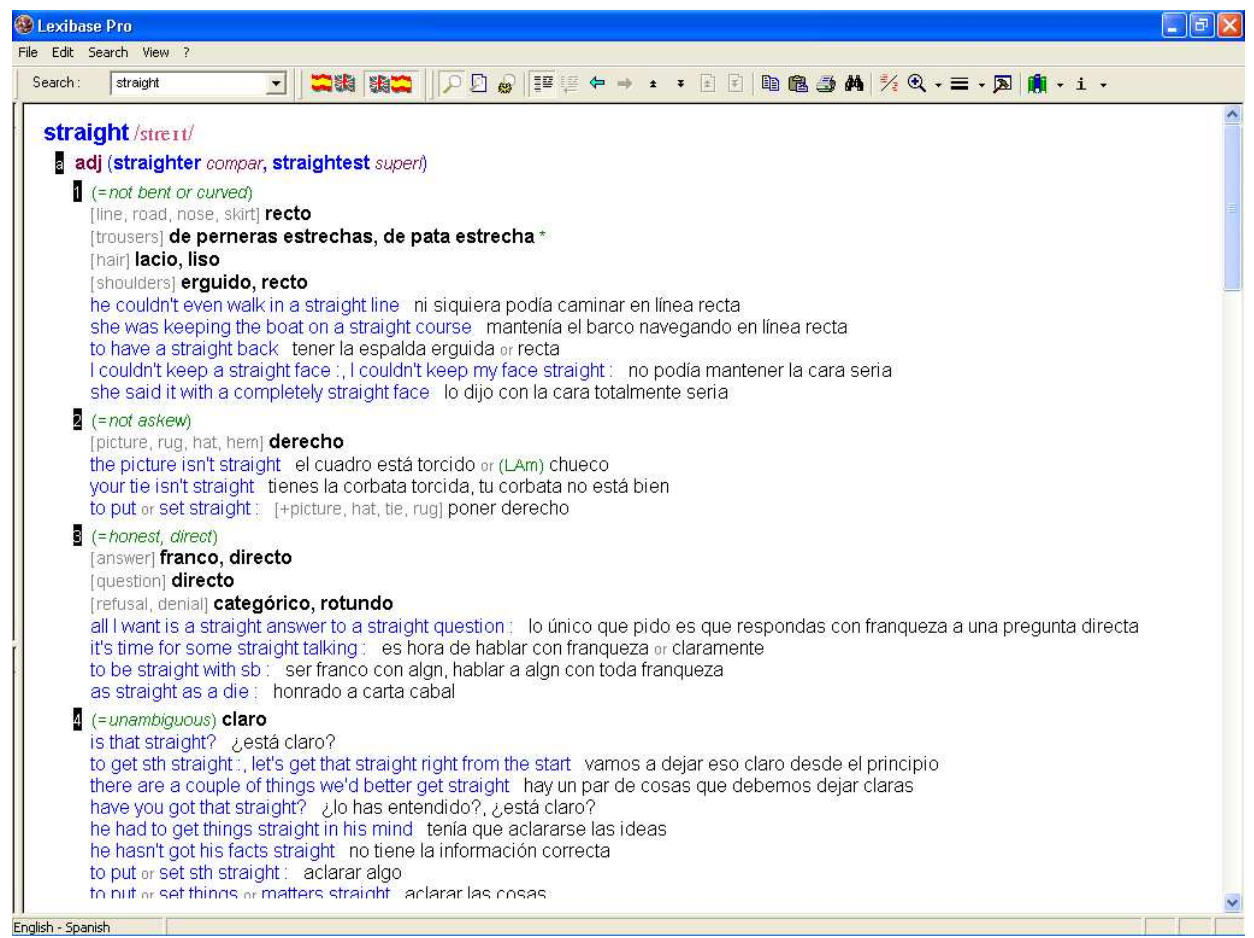


HUMBLÉ - Os estudos da tradução e os dicionários

Nesta página, o lexicógrafo não teve muita escolha ao traduzir 'straight (line, road, nose, skirt)' por 'recto' nem ao traduzir 'as straight as a die' por 'honrado a carta cabal'. O que pode ser discutido é, no máximo, se ele teve razão ao traduzir a expressão por essa, e não por outra, por razões de freqüência de uso.

Agora, em todos os momentos em que ele teve que inventar alguma coisa, imaginar alguma situação em que uma determinada expressão podia ser usada, ele teve que escolher. Primeiro, houve a escolha da situação e, depois, a escolha da tradução. Nesse último momento, ele teve que exercer o bom senso para escolher e não somente fazer uso da memória. A prova disso é que as mesmas expressões, 'postas a funcionar' dentro de uma sequiência imaginada, produzem traduções diferentes, não só quando comparamos dois dicionários, mas também quando comparamos varias ocorrências dentro de um mesmo dicionário. Assim o Lexibase dá várias alternativas para a expressão 'to get .. straight'

Let's get that straight right from the start

Vamos a dejar eso claro desde el principio

There are a couple of things we'd better get straight

Hay un par de cosas que debemos dejar claras

Have you got that straight?

¿Lo has entendido? ¿está claro?

He had to get things straight in his mind

Tenía que aclararse las ideas

O Oxford, por sua vez, dá igualmente várias opções para uma alternativa ainda mais coercitiva porque ela é composta de um número maior de palavras: 'to set the record straight'. Quanto menos palavras o contexto tem, mais opções de tradução há.

I went to see the boss to set the record straight

fui a ver al jefe para aclarar las cosas

just to set the record straight, I never actually said that que conste que yo nunca dije eso

O que, para mim, caracteriza a tradução stricto sensu, a tradução como o termo se entende tradicionalmente, é a possibilidade de escolha. A tradução lato sensu, por outro lado, seria a tradução onde existe somente uma única alternativa certa, ou seja, onde não há escolha. É o caso da tradução terminológica, onde 'mioceno' é 'Miocene' e 'miocárdio' é 'myocardium'.

Assim, um trecho como 'um rapaz aqui do bairro, que eu conheço de vista' pode ser traduzido de várias maneiras. 'Um rapaz' pode ser 'a bloke, a guy, a chap, a boy'. 'Bairro' 
Trab.Ling.Aplic., Campinas, 44(2) - Jul./Dez. 2005

pode ser 'area', 'neighbourhood', 'district' e assim por diante. Esta seria uma tradução stricto sensu.

O dicionário bilíngüe consiste somente em parte em traduções lato sensu: palavras ou frases que possuem uma só tradução, porque aparecem em um só contexto, ou porque o lexicógrafo fez tudo para primeiro catalogar e depois explicitar os diferentes contextos nos quais a palavra pode aparecer ('bala' num contexto 'culinário' só pode ser 'sweet', 'bonbon', 'caramelo'). No caso de 'bala', quem vai traduzir realmente é o tradutor que vai escolher entre as diferentes alternativas, não o lexicógrafo, que deu todas as equivalências possíveis.

No caso do dicionário, a possibilidade de escolha na tradução aparece somente onde houver alguma escolha exercida previamente pelo lexicógrafo-autor do exemplo. Isto pode ter sido na redação (se o exemplo foi inventado) ou na eleição (se o exemplo foi extraído de um corpus). Assim, para exemplificar a palavra espanhola 'cierto', o lexicógrafo poderia inventar um exemplo como 'las monedas nacionales se mantendrían en uso durante un cierto tiempo'4. Aqui ele escolheu falar de 'moedas', 'nacionais' que 'se manteriam em uso' etc. e nada disso foi ditado inelutavelmente pela natureza da palavra 'cierto'.

Num dicionário bilíngüe costumam trabalhar no mínimo dois tipos de lexicógrafos: um para cada língua. Um que produz os exemplos, um outro que os traduz. Do mesmo jeito o lexicógrafo-tradutor terá que escolher as palavras ao fazer a tradução do exemplo. A tradução stricto sensu aparece quando o lexicógrafo inventor do exemplo pôde escolher palavras para formar um exemplo e o lexicógrafo-tradutor teve que escolher palavras para traduzir este exemplo.

No caso de exemplos, a possibilidade de escolha opera a dois níveis diferentes. Primeiro, na produção do próprio exemplo. Segundo, na sua tradução. Esta possibilidade não existe quando se trata de palavras, nem de provérbios, nem de grupos de palavras que só por contingências histórico-ortográficas não configuram uma só palavra (em cima vs. encima, of course vs. ofcourse). Os exemplos para 'wrong', como aparecem no verbete do Larousse, podem ser classificados de diferentes maneiras.

\section{‘WRONG’ EM TRÊS DICIONÁRIOS BILÍNGÜES INGLÊS-FRANCÊS}

Se não há publicações sobre a incidência de problemas de tradução nos dicionários, pode-se assumir que este tipo de tradução não esteja sendo visto como problemático. No entanto, basta considerar algumas traduções de exemplos encontrados em três dicionários bilíngües francês-inglês de grande porte (Oxford-Hachette, Collins e Larousse), todos igualmente confiáveis, para perceber que a objetividade com a qual acostumamos abordar os dicionários - como se a escolha e, portanto, o erro não existisse -, é ilusória.

\footnotetext{
${ }^{4}$ Exemplo do Collins Lexibase Pro Inglés-Español.
} 


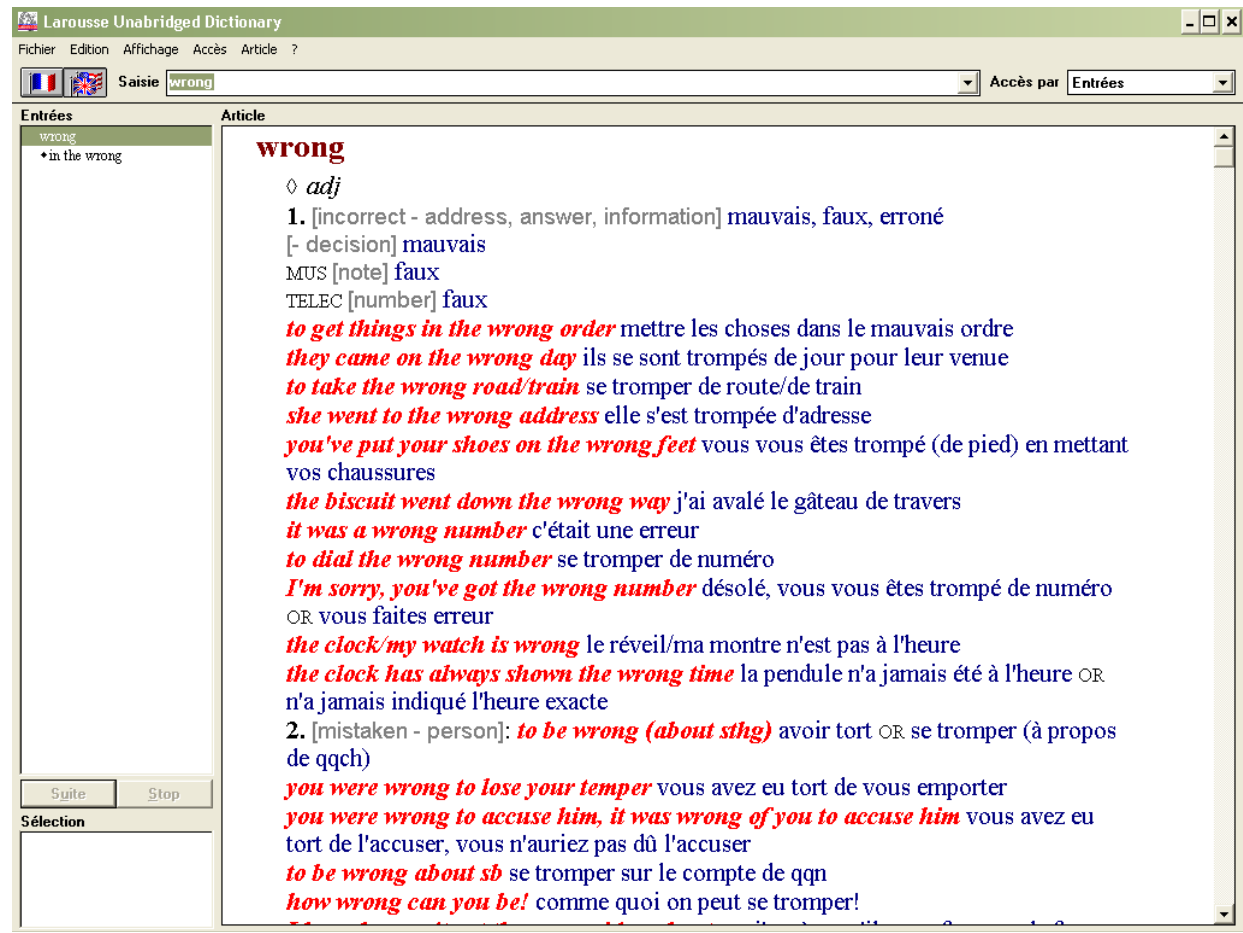

Se formos analisar este verbete, as traduções de 'wrong', 'mauvais, faux, erroné', não são traduções propriamente dito, nem o é a expressão 'to get things in the wrong order; mettre les choses dans le mauvais ordre'. Mas sim é uma tradução 'they came on the wrong day ; ils se sont trompés de jour pour leur venue', porque, no último caso, they poderia ter sido substituído por qualquer outra pessoa (I, you, etc.), came por qualquer outro verbo ou tempo (went, will come, etc.) e day por qualquer outra indicação de tempo (at the wrong hour, etc.), levando em conta as restrições lexico-gramaticais (*on the wrong hour). Claro que quase todas as frases que costumam aparecer como exemplos num verbete padecem de um alto grau de fixação. Exemplos como 'they came on the wrong day; ils se sont trompés de jour pour leur venue' ou 'she went to the wrong address; elle s'est trompée d'adresse' não brilham por sua originalidade. Nem poderiam ser muito originais porque, se fossem, eles deixariam de ser 'exemplos', ou seja, deixariam de ser orações nas quais qualquer usuário poderia reconhecer um molde para aquilo que ele gostaria de encodar ou descodificar.

Agora, esses pontos de vista 'evidentes' não deixam de ser interessantes, especialmente num verbete como 'wrong' onde prevalece o que se considera como 'moralmente aceitável'. 
Trab.Ling.Aplic., Campinas, 44(2) - Jul./Dez. 2005

Isso é demonstrado por frases como "you were wrong to lose your temper ; vous avez eu tort de vous emporter", "slavery is wrong; l'esclavage est inacceptable", "it was wrong of him to take the money ; ce n'était pas bien de sa part de prendre l'argent", ou até mesmo “what's wrong with reading comics? ; qu' est-ce qu'il y a de mal à lire des bandes dessinées?", que são frases que dão uma boa idéia do que um sociedade acha normal ou anormal numa determinada fase da sua evolução. Um dicionário necessariamente tem que registrar o que a grande maioria do seu público aceita como normal porque isso é o 'texto' que falta, a 'Purloined Letter' de Poe: à vista de todos e invisível por essa mesma razão.

\section{'FAR WRONG'}

Nos mesmos dicionários já analizados achamos no verbete 'wrong' a expressão 'far wrong', relativamente fixa, mas que permite algumas variações como 'won't go far wrong', 'can't go far wrong', 'was not far wrong' e algumas outras parecidas, sempre no modo negativo. Os três dicionários optaram pelo uso de uma segunda pessoa, junto com a forma won't e a conjunção if.

\begin{tabular}{|l|l|l|}
\hline Oxford Hachette & Collins & Larousse \\
\hline you won't go far wrong if... & $\begin{array}{l}\text { you won't go far wrong if } \\
\text { you .. }\end{array}$ & $\begin{array}{l}\text { you won't go far wrong } \\
\text { if you follow her advice }\end{array}$ \\
$\begin{array}{l}\text { vous ne risquez pas de faire } \\
\text { fausse route si... }\end{array}$ & $\begin{array}{l}\text { vous ne pouvez guère vous } \\
\text { tromper si vous.. }\end{array}$ & $\begin{array}{l}\text { vous ne risquez guère de } \\
\text { vous tromper si vous conseils } \\
\text { suivez ses }\end{array}$ \\
\hline
\end{tabular}

Nos três dicionários aparecem exemplos quase idênticos que foram, no entanto, traduzidos de três maneiras diferentes. Houve, portanto, possibilidade de escolha e se trata, portanto, de uma tradução sensu estrito. ${ }^{5}$ Quais foram as considerações que estiveram à base das traduções do lexicógrafo nos dicionários estudados?

${ }^{5}$ Em que medida o que é sugerido como tradução é, além de gramaticalmente plausível, realmente usado? Usando certa cautela, a ferramenta de busca Google pode nos dar uma idéia. A alternativa Oxford vous ne risquez pas de faire fausse route não aparece nenhuma vez no Google (o trecho 'pas de faire fausse route' aparece cinco vezes e 'faire fausse route' três mil). A alternativa Collins vous ne pouvez guère vous tromper aparece três vezes no Google (a parte 'guère vous tromper' aparece seis). No caso do Larousse, vous ne risquez guère de vous tromper aparece três vezes ('vous ne risquez guère' aparece sessenta vezes). Há, portanto, uma primeira diferença, que é de frequiência. A combinação sugerida pelo Oxford não aparece nenhuma vez, mas as combinações sugeridas pelos outros dois dicionários também não parecem muito. 
O uso da palavra 'guère', usada por Collins e Larousse, indica um registro escrito. Além disso, os três dicionários traduziram you pelo formal vous (a não ser que you seja entendido como vocês, o que é improvável). Houve portanto escolha de um registro formal, não necessariamente presente no original.

Ademais, o Oxford escolheu traduzir uma metáfora de 'viagem, passeio', presente no verbo 'go', por uma metáfora do mesmo tipo: 'route'. Os dois outros dicionários escolheram traduzir a metáfora pela palavra mais genérica e abstrata 'se tromper' (to make a mistake, to be wrong). Nem Oxford, nem Larousse, nem Collins mencionam 'go far wrong' como uma tradução possível no seus respectivos verbetes para 'tromper', o que indica que realmente se trata de uma metáfora. Os lexicógrafos não pensaram espontaneamente em 'go far wrong' ao traduzir 'tromper', mas pensaram todos em 'tromper' ao traduzir 'go far wrong'.

A suposta objetividade dos dicionários, dada por certa pela maioria de seus usuários, foi rapidamente aniquilada. Nos exemplos analisados, os lexicógrafos realmente tiveram que ser tradutores e tiveram que fazer escolhas. A situação deste tipo de tradutor, no entanto, é cercada por restrições diferentes das que limitam o trabalho do tradutor literário. $\mathrm{O}$ tradutor literário faz escolhas levando em conta convicções pessoais como: 'estrangeirizar ou integrar', sentido-por-sentido ou palavra-por-palavra, arcaizar ou modernizar, além de exigências editoriais. Em outras palavras, os problemas que este tradutor teve que enfrentar são os mesmos dos tradutores literários, por muito estranho que isso pareça. Não são os problemas dos tradutores técnicos.

\section{'GO WRONG'}

No caso da expressão 'go wrong', os três dicionários pesquisados escolheram exemplos idênticos que, na versão inglesa original, no entanto, não pareciam permitir muita escolha. Prevalece a segunda pessoa you com a forma verbal can't. Depois do simples 'you can't go wrong' seguem outros exemplos, que acrescentam ao exemplo original situações que afinam a tradução. Os lexicógrafos do Collins e do Hachette escolheram fazer exemplos mais longos. 


\begin{tabular}{|l|l|l|}
\hline Oxford Hachette & Collins & Larousse \\
\hline \multirow{2}{*}{ you can't go wrong } & you can't go wrong & you can't go wrong \\
\hline $\begin{array}{l}\text { (in choice of route) } \\
\text { tu ne peux pas te tromper }\end{array}$ & $\begin{array}{l}\text { (on road) c'est très simple, il } \\
\text { est impossible de se perdre }\end{array}$ & $\begin{array}{l}\text { vous ne pouvez pas vous } \\
\text { tromper, c'est très simple }\end{array}$ \\
\hline $\begin{array}{l}\text { (are bound to succeed) } \\
\text { tu peux être tranquille. }\end{array}$ & $\begin{array}{l}\text { (in method etc.) c'est simple } \\
\text { comme bonjour }\end{array}$ & $\begin{array}{l}\text { you can't go wrong with a } \\
\text { pair of jeans } \\
\text { vous êtes tranquille avec un } \\
\text { jean }\end{array}$ \\
\cline { 2 - 4 } & $\begin{array}{l}\text { (in choice of job, car etc.) (de } \\
\text { choute façon) c'est un bon } \\
\text { choix }\end{array}$ & $\begin{array}{l}\text { you can't go wrong with a } \\
\text { good book } \\
\text { [for reading] vous ne } \\
\text { risquez pas de vous } \\
\text { ennuyer avec un bon livre; }\end{array}$ \\
\hline & $\begin{array}{l}\text { Super Deluxe } \\
\text { (de toute façon) une Super } \\
\text { Deluxe, c'est un bon choix }\end{array}$ & $\begin{array}{l}\text { [as present] un bon livre, } \\
\text { cela plaît toujours }\end{array}$ \\
\hline
\end{tabular}

Na maioria dos exemplos expandidos, as rubricas evocam um 'texto', uma situação que o usuário teria que comparar com a sua. A semelhança com deixas de teatro é evidente, a mimesis de uma situação real é evocada imediatamente.

Uma vantagem que o lexicógrafo-tradutor tem sobre outros tradutores é que ele pode colocar várias alternativas de tradução uma atrás da outra, além de 'itens opcionais', como 'de toute façon', entre parênteses. O usuário é que vai 'ter que se virar'. Como é ele que tem o texto em mãos, a responsabilidade do lexicógrafo-tradutor é limitada e é de se esperar que ele seja elogiado por ter colocado mais de uma tradução possível, elogio que um tradutor comum não pode esperar. 
HUMBLÉ - Os estudos da tradução e os dicionários

\section{A TRADUÇÃO E O TEXTO}

A tradução de exemplos esbarra no fato de eles não serem texto. Voltemos a um dos exemplos citados de wrong, aquele que, por seu tamanho, mais se parece com um texto "you won't go far wrong if you follow her advice / vous ne risquez guère de vous tromper si vous suivez ses conseils". Percebemos que o lexicógrafo fez o possível para evocar uma pequena 'tranche de vie' em que a expressão a ser ilustrada poderia ter uma função real, comunicativa.

O uso de uma segunda pessoa fez nascer um diálogo. Esta personagem, nós podemos imaginar que seja um funcionário público falando para outro, talvez seu superior, já que ele formula sua frase com certa cautela (you won't go far wrong). Ele se sente mais inseguro ainda, aparentemente, porque, além disso, ele recomenda a opinião de uma mulher (her advice), detalhe que, aliás, desaparece na tradução (ses conseils) e que desapareceria também numa tradução culta para o português (seus conselhos).

Ou podemos ainda pensar numa velha condessa que acaba de aconselhar um jovem sobre sua intenção de romper o namoro e o mordomo, ao fechar a porta, o aconselha a realmente seguir seus conselhos. Tudo isso são imagens que surgem instantaneamente na mente de quem estiver consultando o dicionário, preocupado com outra história, a do seu texto, talvez também imaginada e que significa a irrupção de um mundo ficcional, cheio de possibilidades, num curso de idéias totalmente alheio a ele.

O exemplo lexicográfico precisa deste mundo ficcional para se tornar útil, para poder ser inserido no contexto de um usuário que, com o mundo imaginado por um breve instante pelo lexicógrafo, não tem relação com o problema que o usuário do dicionário quer resolver. O lexicógrafo necessita o lampejo literário, por breve que seja, para poder fazer seu trabalho. A ficção é um passo imprescindível à aproximação de uma certa objetividade. Contudo, como a ficção é necessariamente 'escolha', é introduzido aqui um elemento de vagueza que contraria o próprio trabalho do lexicógrafo: a de ser uma ferramenta neutra e imparcial.

Existe a possibilidade de reduzir tudo isso a um mínimo, de traduzir tão somente a 'palavra' -'infarctus' é ‘infarto'-e eliminamos imediatamente as tentações ficcionais. Mas quanto mais as palavras são comuns, mais precisamos de outras para dar-lhes sentido e a tentação ficcional ressurge.

Há muitos exemplos nos dicionários que acabamos de analisar. Vou citar um. Veja a seqüência encontrada sob 'thing' no Collins English-French:

such things as money, fame .. / des choses comme l'argent, la gloire .. ; he's interested in ideas rather than things / ce qui l'intéresse ce sont les idées et non pas les objets ; things of the mind appeal to him / il est attiré par les choses de l'esprit. E na sequiência e em oposição a tudo isso: the thing he loves most is his car / ce qu'il aime le plus au monde c'est sa voiture.

Como pode ser percebido nesta coletânea, vem junto com a tentação ficcional a tentação educativa, a de lecionar o usuário. Vemos retratados um ‘bom' e um 'mau', aquele 
que se interessa por idéias e aquele que se interessa por carros. É lógico que o lexicógrafo escolhe o lado de quem escolhe as idéias e não daquele que se interessa por carros, gosta de velocidade e de bravatear. Não podemos conceber uma inversão tal como 'the thing he loves most is his ideas / ce qu'il aime le plus au monde c'est ses idées'. Seria um exemplo que qualquer usuário acharia estranho, embora gramaticalmente correto, e ilustrador, tão bem quanto o outro, do uso de 'thing' nesta acepção.

O lexicógrafo, portanto, é limitado na criação do seu mundo ficcional pelo que é geralmente aceito como fisicamente possível (uma tartaruga não é mais rápida que um avião), e como um consenso moral (as idéias são mais nobres do que os carros). São estes os limites dentre os quais se move a liberdade do lexicógrafo-criador de exemplo e a maneira como se limita o trabalho do lexicógrafo-tradutor. O desconcerto que causaria um exemplo como 'a coisa que ele mais gosta são suas idéias' tornaria o trabalho de tradução problemático porque o leque de escolhas que o tradutor teria que examinar seria simplesmente amplo demais.

Ao ler o exemplo 'o que ele mais ama é o seu carro', imaginamos um homem de uns 45 anos, reclinado no pára-lamas de um conversível, paletó estreito, chapéu, que olha sorridente para nossa câmera interior. Imaginamos esta cena, ou algo parecido, e depois do 'uso' do exemplo, esquecemos.

O exemplo contrário, 'a coisa que ele mais ama são suas idéias', abre um leque de imagens amplíssimo. Ou nos dá um branco, nos deixa pensativos sobre o que é que se supõe que o usuário teria que imaginar. A frase é traduzível, mas não funciona como exemplo.

\section{CONCLUSÃO}

Resumindo, podemos fazer uma distinção entre exemplos curtos, que se assemelham à tradução de palavras, e exemplos mais longos, que se assemelham a textos.

Quando os exemplos são curtos, há diferenças na tradução devido a razões como:

- os hábitos de fala do próprio tradutor;

- a maneira do lexicógrafo tradutor de entender o exemplo;

- o objetivo do dicionário;

- e, na falta de uma apólice clara, o que o tradutor acha que é o objetivo do dicionário.

Quando os exemplos são mais longos, mais complexos, entra a 'ficcionalização'. Para poder traduzir, o tradutor tem que imaginar um contexto devido à falta de texto. Contudo, esta imaginação é uma ficcionalização que só é possível se o exemplo ficar dentro de certos limites. Para poder ser traduzido, o exemplo tem que se sujeitar às balizas da verossimilhança física e da desejabilidade moral. Só pode ser traduzido o que é um lugar comum, uma trivialidade. Se o exemplo original não for, de alguma forma, um lugar comum, o 'texto faltando' não consegue ser imaginado. O lexicógrafo só pode traduzir se ele conseguir imaginar em que situação o exemplo pode ser usado. Neste leque de 
possibilidades, o lexicógrafo terá necessariamente que escolher e suas escolhas coincidirão só ocasionalmente com as dos seus colegas. A tradução, que o usuário terá normalmente como verdade absoluta, não é, na realidade, o resultado do poder de imaginação do lexicógrafo e, sim, uma das possibilidades.

Estranhamente, o lexicógrafo-tradutor tem que passar pela ficção e sua ficção pode nem sempre coincidir com a ficção criada pelo autor do exemplo. É uma regra que vale para qualquer texto, mas um exemplo de dicionário é só um princípio de texto, um núcleo de texto. As deficiências de tradução não podem ser compensados no resto do texto e o exemplo tem que obedecer a certos critérios para poder ser traduzido.

\section{REFERÊNCIAS BIBLIOGRÁFICAS}

\section{Dicionários pesquisados}

Larousse Grand Dictionnaire Français Anglais / Anglais Français 1996 Versão eletrônica Oxford-Hachette 1996 Superlex Versão eletrônica Collins English French Dictionary Versão eletrônica

\section{Literatura secundária}

ATKINS, B. T. S. (Ed.) (1998). Using Dictionaries. Studies of Dictionary Use by Language Learners and Translators. Niemeyer.

HALLIDAY, M. A. K. (1985 ). An Introduction to Functional Grammar, Edward Arnold, London.

HAUSMANN, F. J. Grundprobleme des zweisprachigen Wörterbuch in Hyldgaard-Jensen K and Zettersten A Symposium on Lexicography III Lexicographica Series Maior 19, Niemeyer, Tübingen.

van STERKENBURG, P. (2003). A practical Guide to Lexicography John Benjamins Amsterdam/Philadelphia

WELKER, H. (2003). Uma pequena introdução à lexicografia, Thesaurus, Brasília.

WILLIAMS, J. and CHESTERMAN, A. (2002). The Map: a beginner's guide to doing research in translation studies, St. Jerome Publishing, Manchester.

ZGUSTA, L. (1971). Manual of Lexicography, Mouton, The Hague, Paris. 